\title{
Characteristic Dermatologic Changes in the Condition of Skin after Ultrasonic Stimulation in Healthy Korean Men
}

\section{So-Jung Kim ${ }^{1 *}$, Seung-Min Yang1* ${ }^{*}$ Ju-Hyun Kim² ${ }^{2}$, Jeong-Uk Lee ${ }^{3}$, Mee-Young Kim¹, Lim-Kyu Lee ${ }^{1,4}$, Byoung-Sun Park1, Won-Deok Lee1, Ji-Woong Noh', Yong-Sub Shin', Doo-Ho Kim1, Il-Hyun Kim¹, Junghwan Kim ${ }^{5}$}

\begin{abstract}
${ }^{1}$ Laboratory of Health Science \& Nanophysiotherapy, Department of Physical Therapy, Graduate School, Yongin University, Yongin, Republic of Korea

${ }^{2}$ Department of Physical Therapy, College of Health Welfare, Wonkwang Health Science University, Iksan, Republic of Korea ${ }^{3}$ Department of Physical Therapy, College of Health Science, Honam University, Gwangsan-gu, Republic of Korea

${ }^{4}$ The Team of Safety and Quality Management, Yeongwol Combined Cycle Power Plant Division, Korea Southern Power Plant, Yeongwol-gun, Republic of Korea

${ }^{5}$ Department of Physical Therapy, College of Public Health \& Welfare, Yongin University, Yongin, Republic of Korea

Email: "junghwankim3@yongin.ac.kr
\end{abstract}

How to cite this paper: Kim, S.-J., Yang, S.-M., Kim, J.-H., Lee, J.-U., Kim, M.-Y., Lee, L.-K., Park, B.-S., Lee, W.-D., Noh, J.-W., Shin, Y.-S., Kim, D.-H., Kim, I.-H. and Kim, J. (2018) Characteristic Dermatologic Changes in the Condition of Skin after Ultrasonic Stimulation in Healthy Korean Men. Journal of Cosmetics, Dermatological Sciences and Applications, 8, 195-206.

https://doi.org/10.4236/jcdsa.2018.84021

Received: September 7, 2018

Accepted: November 9, 2018

Published: November 12, 2018

Copyright $(0) 2018$ by authors and Scientific Research Publishing Inc. This work is licensed under the Creative Commons Attribution International License (CC BY 4.0).

http://creativecommons.org/licenses/by/4.0/

(c) $\underset{\mathrm{EY}}{\text { (i) Open Access }}$

\begin{abstract}
The aim of our study was to recognize different skin conditions of the face and neck using six biophysical parameters and to show the changes after the application of ultrasonic stimulation (US). We assessed the differences in the sebum, moisture, pores, wrinkles, pigmentation, and elasticity of the skin in the face and neck regions. A total of 30 healthy men in their 20 s were enrolled. We used a skin diagnosis meter to assess the state of the skin. The sebum and pores of the face were more significant than in the neck. The amount of moisture in the U-zone was significantly higher than in other areas. Statistical differences were found between the pre- and post-measurement values in the sebum, moisture, wrinkles and pigmentation. Wrinkles and pigmentation were positively correlated. Our data showed that the changes in skin condition are associated with external stimulants. The effect of US on skin may differ depending on the part of the body, and some biophysical properties of skin vary depending on the location on the body.
\end{abstract}

\section{Keywords}

Ultrasonic Stimulation, Korean Men, Skin

*The authors contributed equally to this work. 


\section{Introduction}

Skin is the outer covering of the body and plays a role in protecting the body from physical and chemical factors [1]. The skin has a major role in thermoregulation of the body, in addition to immunological, sensory, and autonomic functions [2]. Regional differences in biophysical skin properties may play a role in the development of localized dermatoses by altering skin hydration, sebum production, and barrier function [3]. Skin conditions may be affected by internal and external factors, such as sex, age, temperature, and humidity [1]. In the domain of physical therapy, ultrasonic stimulation (US) is used to help in recovery from acute, chronic injures and disease of soft tissue. US is now being adopted in various drug delivery and other therapeutic applications [4]. Sonophoresis is the application of US to enhance skin permeability vis-à-vis a variety of molecules [5]. The physiological effects of US on tissue can be thermal or non-thermal [6] [7]. Thermal effects include the increased extensibility of collagen fibers and increased blood flow [6]. Non-thermal effects include cavitation, the acoustic activation of fibroblasts, increased protein synthesis, and tissue regeneration [7]. Some previous studies have found that US enhances the synthesis of collagen by fibroblasts and increases the temperature of soft tissue, which increases the metabolic rate and accelerates tissue repair [8] [9]. As used in medicine and physiotherapy, therapeutic US usually involves frequencies between 1 and $3 \mathrm{MHz}$ [10]. Few studies have reported the effect of US on fracture healing, musculoskeletal disorders, and tissue temperature [11] [12]. Luebberding et al. assessed the differences in skin localization using four parameters related to aged change [1]. Men et al. assessed the differences in the skin surface $\mathrm{pH}$, sebum content, and stratum corneum hydration at various ages and in both genders in a large Chinese population without skin diseases. They concluded that these parameters vary with age, gender, and body location [13]. Alireza et al. found variations in biophysical parameters of the skin with age, gender, and body region [14]. In the present study, we divided the faces in detail and compared them before and after US. The aim of this study was to establish a map of the facial skin using six biophysical parameters to study various aspects of the skin-sebum, moisture, pores, wrinkles, pigmentation, and elasticity.

\section{Methods}

\subsection{Participants}

Fifteen healthy male subjects aged 19 - 26 were enrolled in this study. None of the subjects had any skin disorders (Table 1). Two areas, the face and the neck, were examined before and after US. No skin care products had been applied for at least $24 \mathrm{~h}$ beforehand, and the skin had not been washed with soap or surfactants for at least $2 \mathrm{~h}$ before the experiment. The participants were asked to complete a questionnaire during individual in-depth interviews, which took $30 \mathrm{~min}$ per person [15]. 
Table 1. The general characteristics of men in their $20 \mathrm{~s}$.

\begin{tabular}{|c|c|c|}
\hline Variable & Classification & \\
\hline Age (yrs) & & $23.9 \pm 0.4$ \\
\hline Height $(\mathrm{cm})$ & & $175.3 \pm 0.7$ \\
\hline Weight (kg) & & $71.3 \pm 2.4$ \\
\hline BMI $\left(\mathrm{kg} / \mathrm{m}^{2}\right)$ & & $23.1 \pm 0.6$ \\
\hline \multirow[t]{2}{*}{ Gender (\%) } & Male & $30(100.0)$ \\
\hline & Female & - \\
\hline \multirow[t]{4}{*}{ Blood type (\%) } & $\mathrm{AB}$ & $4(13.3)$ \\
\hline & A & $12(40.0)$ \\
\hline & B & $10(33.3)$ \\
\hline & $\mathrm{O}$ & $4(13.3)$ \\
\hline \multirow[t]{2}{*}{ Smoking (\%) } & Smoker & $3(10.0)$ \\
\hline & Nonsmoker & $27(90.0)$ \\
\hline \multirow[t]{4}{*}{ Drinking (\%) } & Yes & $29(96.7)$ \\
\hline & No & $1(3.3)$ \\
\hline & 1 bottle/week & $20(69.0)$ \\
\hline & 2 bottle/week & $9(31.0)$ \\
\hline PSQI (score) & & $2.2 \pm 0.1$ \\
\hline \multirow[t]{3}{*}{ Skin injury (\%) } & Injuries experience & $22(73.3)$ \\
\hline & Injuries inexperience & $8(26.7)$ \\
\hline & Don't know & - \\
\hline \multirow[t]{4}{*}{ Type of skin injury (\%) } & Abrasion & $15(68.2)$ \\
\hline & Burns & $6(27.3)$ \\
\hline & Incised wound & $1(4.5)$ \\
\hline & Nothing & $8(26.7)$ \\
\hline
\end{tabular}

All data were presented as the mean \pm SE. BMI, body mass index; PSQI, Pittsburgh sleep quality index.

\subsection{Measurements}

All measurements were performed with the participants comfortably in a supine position. The face was divided into two areas, the $\mathrm{T}$ zone and the $\mathrm{U}$ zone. The $\mathrm{T}$ zone was divided into four areas-FTP1 (the right side of the forehead), FTP2 (the midpoint of the trichion and the crossing point of the line connected by both the frontotemporal and median sagittal lines with respect to the sagittal axis), FTP3 (the left side of the forehead), and FTP4 (both sides of the nose). The U zone was divided into three areas-FUP1 (the righthand cheilion), FUP2 (the lefthand cheilion), and FUP3 (the pogonion). The neck was divided into three areas-NP1 (the righthand midpoint of the lateral surface of the mastoid process and the lateral third of the clavicle), NP2 (the point of laryngeal prominence), and NP3 (the lefthand midpoint of the lateral surface of the mastoid process and 
the lateral third of the clavicle). Repeated measurements were taken for each study subject. US was used in the experimental stimulation of the skin and emitted between $0.46 \mathrm{kHz}$ and $0.68 \mathrm{kHz}$. Normal contact gel was used as a coupling medium. A skin diagnosis meter (SDM, 2016 BOMTECH ver. 3.20) was used to measure the skin's surface sebum content, moisture, pores, pigmentation, wrinkles, and elasticity of the face and neck. US was applied to each region for 15 min, with the distance between the measuring device and the subject's skin being set at $20 \mathrm{~cm}$. During the measurement of the skin, the normal force level was 0.7 $\mathrm{N}$. The same investigator performed all procedures in a room kept at a constant temperature $\left(22^{\circ} \mathrm{C}-24^{\circ} \mathrm{C}\right)$ and humidity $(45 \%-55 \%)$. The skin testing machine is made up of two meters: the E-cam measures sebum, pigmentation, and pores, and the P-sensor measures moisture and elasticity. The E-cam measures the skin using an X80 lens and measures the amount of sebum using UV light. The meter measures the dermis layer of pigmentation, wrinkle length, and pore size using general light. The measurement area is in the range of $4 \mathrm{~cm}^{2}$. The P-sensor uses an electrode to send a current through the skin surface and the skin reacts to the electricity. It creates a calculation using the values of the skin's reaction to the electricity. To measure sebum, the meter uses skin UV to see how much oil is contained in the targeted area [16].

\subsection{Clinical Assessments}

We used the sebum arbitrary units (SAUs); the values are 0 - 650 (a little sebum), 650 - 1200 (normal), 1200 - 5000 (a lot of sebum), and more than 5000 (excessive sebum). To make use of the moisture arbitrary units (MAUs), set the values to $1 \%-100 \%$. These values are $0-19$ (very dry), $20-29$ (dry), $30-39$ (moderate), 40 - 49 (plenty of moisture), and more than 50 (a high amount of moisture) [17]. The P-sensor meter uses a rectangular spring to measure elasticity. When the spring contacts the skin, it measures how much the sticky part of the spring can be forced into the skin. To make use of the elasticity arbitrary units (EAUs), set the values to $1 \%-100 \%$. These values are $0-24$ (very low elasticity), 25 - 34 (low), 35 - 44 (moderate), 45 - 54 (high), and more than 55 (very high). The graph of elasticity was analyzed by Riemann integration, which the formula for the area is given in equation (Figure 3(A-b)). These values were expressed on a graph. The graph showed the skin surface's reactivity value according to the distance from the point measured. The data values were measured using Microsoft Office Power Point 2007. Based on the x-axis of 0 to $25.5 \mathrm{~cm}$ and the y-axis of 0 to $20 \mathrm{~cm}$, each coordinate was set on the basis of each vertex of the graph. By connecting the set coordinates, we found the area of the graph [17]. Next, each vertex of the graph was calculated using digital calipers (Industrial Instrument Company, Mitutoyo, Japan), and the area was calculated using OriginPro 2016 (64 bit). Pigmentation was measured using general light [18] [19]. The pigmentation arbitrary units (PiAUs) are set at values of 1-10 grade: 0 - 2 (favorable), 2 - 4 (moderate), 4 - 6 (mild), and 6 - 10 (severe). To make use of the wrinkle arbitrary units (WAUs), set the values to $1-10$ grade. These are $0-2$ 
(favorable), 2 - 3 (early mild wrinkles), 3 - 5 (early severe wrinkles), 5 - 6 (thicker mild wrinkles) [20], and $6-10$ (thicker severe wrinkles). To make use of the pore arbitrary units (PAUs), set the values to $1-10$ grade. These are $0-2$ (small size), 2 - 4 (moderate), 4 - 6 (broadish), 6 - 8 (large), and 8 - 10 (very large).

\section{Results}

\subsection{A Comparison of Skin Conditions before and after Ultrasound Stimulation}

In terms of sebum and moisture, a statistical difference was found between the values before US (sebum: $1164.21 \pm 70.94$; moisture: $60.64 \pm 1.70, \mathrm{p}<0.05$ ) and after US (sebum: $955.76 \pm 63.37$; moisture: $66.26 \pm 1.49, \mathrm{p}<0.05$ ) (Figure 1(A) and Figure $1(B))$. In terms of the condition of the pores and the elasticity of the skin, no statistical difference was found between the values before US (pore: 1.08 \pm 0.25 ; elasticity: $57.46 \pm 1.63, \mathrm{p}>0.05$ ) and after US (pore: $0.80 \pm 0.10$; elasticity: $57.97 \pm 1.52, p>0.05$ ) (Figures $1(C)$ and Figure 3 ). In terms of wrinkles and pigmentation of the skin, statistical differences were found between the values before US (wrinkles: $5.66 \pm 0.14$; pigmentation: $4.83 \pm 0.13 \mathrm{p}<0.05$ ) and after US (wrinkles: $5.26 \pm 0.09$; pigmentation: $6.25 \pm 0.13, \mathrm{p}<0.05$ ) (Figure 2).

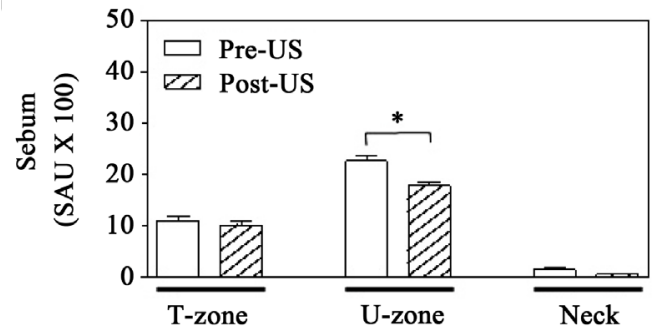

(A)

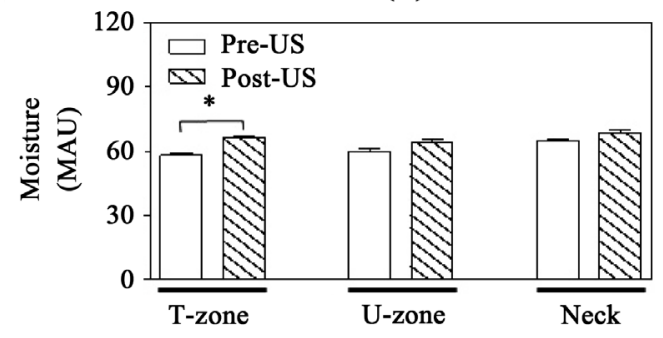

(B)

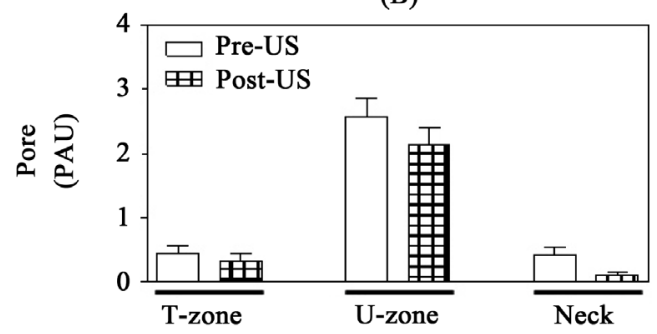

(C)

Figure 1. Differences in the sebum, moisture, and pore of the skin's surface for the face and neck. Each bar represents the mean \pm SE. SAU, sebum arbitrary units; MAU, moisture arbitrary units; PAU, pore arbitrary units; US, ultrasonic stimulation. ${ }^{*} \mathrm{p}<0.05$. 


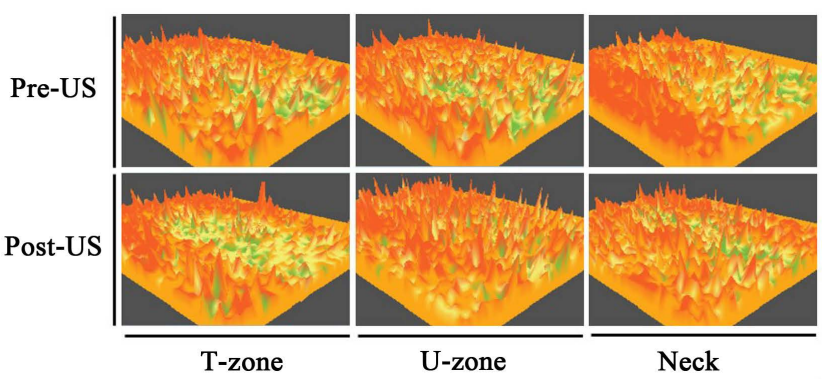

(A)

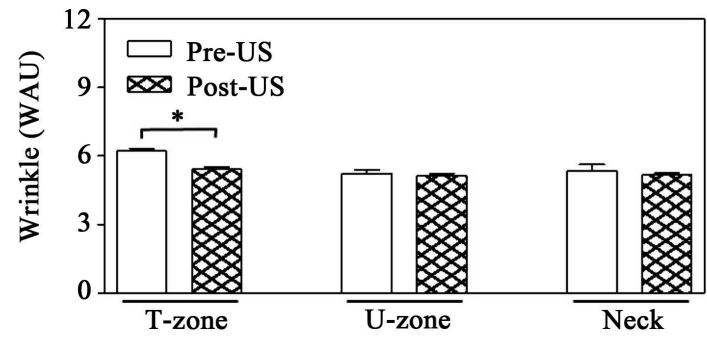

(B)

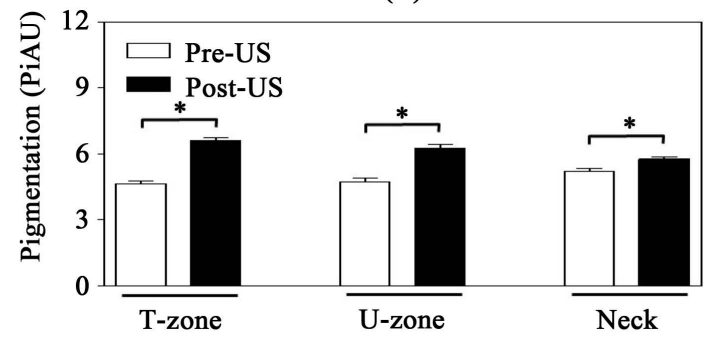

(C)

Figure 2. Differences in the wrinkle and pigmentation of the skin's surface for the face and neck. Each bar represents the mean \pm SE. WAU, wrinkle arbitrary units; PiAU, pigmentation arbitrary units; US, ultrasonic stimulation. ${ }^{*} \mathrm{p}<0.05$.

\subsection{A Comparison of Face and Neck Skin Condition}

A statistical difference in sebum was found between the face (1470.11 \pm 79.48$)$ and the neck $(103.03 \pm 46.82, \mathrm{p}<0.05)$, and a statistical difference was also found in the pores between the face $(1.23 \pm 0.16)$ and the neck $(0.26 \pm 0.09, \mathrm{p}<$ 0.05 ) (Figure 1(A) and Figure $1(\mathrm{C})$ ). No statistical difference in moisture was found between the face $(62.08 \pm 1.51)$ and the neck $(66.65 \pm 1.85, \mathrm{p}>0.05)$, in wrinkles between the face $(5.55 \pm 0.10)$ and the neck $(5.26 \pm 0.18, \mathrm{p}>0.05)$, in pigmentation between the face $(5.58 \pm 0.13)$ and the neck $(5.48 \pm 0.09, \mathrm{p}>0.05)$, or in elasticity between the face $(57.58 \pm 1.50)$ and the neck $(58.03 \pm 1.81, \mathrm{p}>$ 0.05) (Figure 1, Figure 2 and Figure 3(A-a), respectively).

\subsection{A Comparison of T Zone, U Zone, and Neck Skin Condition}

The sebum value for the $U$ zone $(2018.60 \pm 122.48)$ was significantly higher than that for the $\mathrm{T}$ zone $(899.21 \pm 93.41)$ and the neck $(103.03 \pm 46.82)$ (Figure $1(\mathrm{~A}))$. The moisture value for the neck $(66.65 \pm 1.85)$ was significantly higher than that for the $\mathrm{T}$ zone $(62.08 \pm 1.36)$ and the $\mathrm{U}$ zone $(62.09 \pm 1.91)$ (Figure $1(\mathrm{~B}))$. The pore value for the $\mathrm{U}$ zone $(2.35 \pm 0.26)$ was significantly higher than that for the 


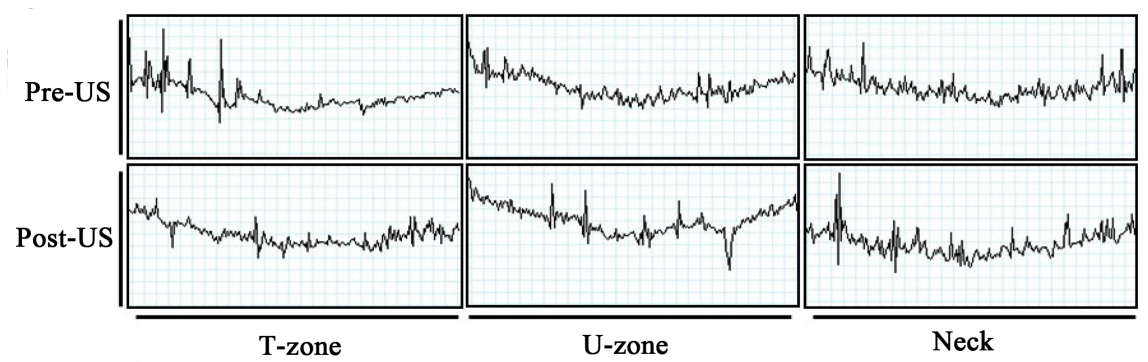

(a)
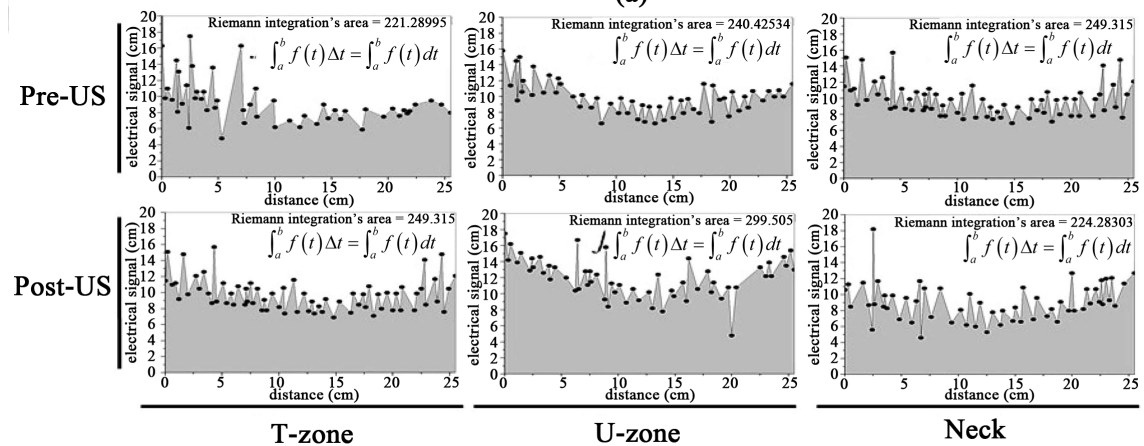

(b)

(A)

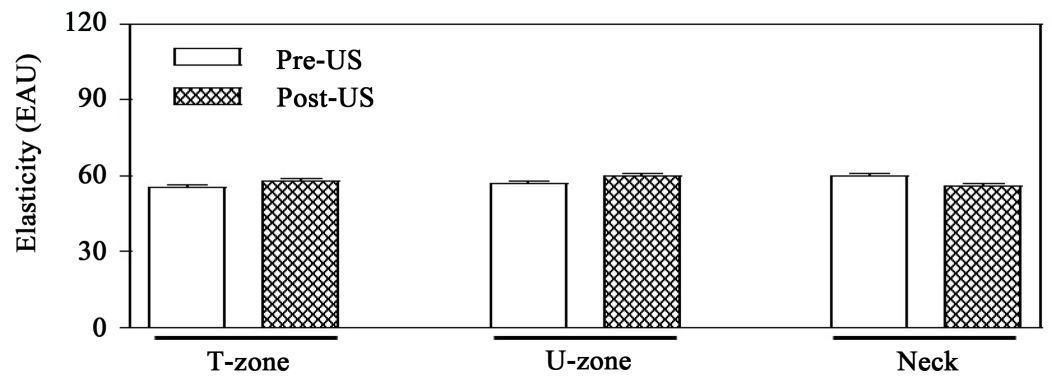

(B)

Figure 3. Differences in the elasticity of the skin's surface for the face and neck. Each bar represents the mean \pm SE. EAU, elasticity arbitrary units; US, ultrasonic stimulation. ${ }^{*} \mathrm{p}<$ 0.05 .

T zone $(0.38 \pm 0.10)$ and the neck $(0.26 \pm 0.09)$ (Figure $1(\mathrm{C}))$. The wrinkle value for the $\mathrm{T}$ zone $(5.81 \pm 0.10)$ was significantly higher than that for the neck $(5.26$ $\pm 0.18)$ and the $U$ zone $(5.19 \pm 0.13)$ (Figure $2(\mathrm{~A})$ and Figure $2(\mathrm{~B})$ ). The pigmentation value for the $\mathrm{T}$ zone $(5.62 \pm 0.14)$ was higher than that for the $\mathrm{U}$ zone $(5.50 \pm 0.17)$ and the neck $(5.48 \pm 0.09)$ (Figure $2(\mathrm{~A})$ and Figure $2(\mathrm{C}))$. The elasticity value for the $U$ zone $(58.50 \pm 1.69)$ was higher than that for the neck $(58.03 \pm 1.81)$ and the $\mathrm{T}$ zone $(56.89 \pm 1.52)$ (Figure $3(\mathrm{~A}-\mathrm{a}))$. We obtained the matching results from the measured values and values using the integral formula (Figure 3(A-b)).

\subsection{Correlation of Skin Condition and the Variables after Ultrasound}

The Pearson's correlation coefficients for the variables are shown in Table 2. In this study, the variables sebum, moisture, pores, wrinkles, pigmentation, and 
Table 2. Pearson's correlation coefficient for skin conditions.

\begin{tabular}{ccccccc}
\hline & Sebum & Moisture & Pore & Wrinkle & Pigmentation & Elasticity \\
\hline Sebum & 1 & & & & & \\
Moisture & 0.293 & 1 & & & & \\
Pore & 0.149 & -0.125 & 1 & & & \\
Wrinkle & 0.074 & $0.585^{* *}$ & -0.051 & 1 & & \\
Pigmentation & -0.171 & 0.087 & 0.117 & $0.420^{*}$ & 1 & \\
Elasticity & $-0.362^{*}$ & $-0.380^{*}$ & -0.104 & -0.200 & -0.314 & 1 \\
\hline
\end{tabular}

Data presented as Pearson's correlation coefficients. ${ }^{*} \mathrm{p}<0.05,{ }^{* *} \mathrm{p}<0.01$.

elasticity were classified. All variables were input as continuous data. The correlation analysis results showed that wrinkles and pigmentation $(\mathrm{r}=0.420, \mathrm{p}<$ $0.05)$ were positively correlated. However, sebum and elasticity $(r=-0.362, p<$ 0.05 ) were negatively correlated (Table 2 ).

\section{Discussion}

The present study is a comparative analysis of the differences in skin condition induced by the application of US in healthy male Korean volunteers. We compared the skin condition of the face and neck before and after US. The correct use of US can induce changes in epidermal calcium, which change the epidermis factors [19]. Our results show that there are differences in the skin condition before and after the application of US to the various regions of the face and neck; specifically, moisture values increased after US. One study reported that the application of glycerin influences the physical properties of skin significantly [20]. Pedersen et al. found that glycerin has a faster plasticizing effect on skin in vivo than water. In addition, glycerin inhibits the transformation of lipids from liquid to solid crystals [20]. Other studies have reported that glycerin diffuses into the stratum corneum, increases skin hydration, and changes skin plasticity [21]. In one study, glycerin was found to be both a humectant and an effective skin moisturizer. The authors assumed that the improved instrument readings were the result of an increase in skin water content [22]. Measurements after the application of US showed significantly lower sebum content and wrinkle, and significantly higher moisture and pigmentation. These results can be explained by the fact that US likely has an effect on mechanical stimulation. Measurements after the application of US revealed significantly lower wrinkle. These results are likely due to improved skin turgor as a result of the US. The reduction in wrinkles points to the spatial rearrangement of the connective tissue structure and an increase in collagen and water content [23]. Many reports have indicated that heat may have a stimulatory effect on the proliferation of human fibroblasts and collagen synthesis during wound healing [24] [25] [26]. In the current study, we suggest that US has an effect on wrinkles. After the application of US, significantly higher skin pigmentation was observed. A previous study reported a relationship between the degree of erythema and that of pigmentation measured at 
$24 \mathrm{~h}$ and $7 \mathrm{~d}$, respectively, after ultraviolet $\mathrm{B}$ (UVB) irradiation. The degree of UVB-induced erythema and pigmentation correlate well linearly [27]. Heating stimulation results in erythema, which is probably a thermal effect [28]. We compared the sebum and pores of various parts of the face and neck and found that the amount of sebum in the skin of the face is higher than that in the skin of the neck and the amount of sebum in the U-zone is higher than in other zones. Some studies have found that in younger people the highest values were found in the central area of the face - the nasolabial and perioral areas and the chin-with the forehead ranking third [29] [30]. Cunliff et al. reported that sebum excretion increases by $10 \%$ as local temperature increases by $1^{\circ} \mathrm{C}$, which suggests that skin temperature plays a role in sebum excretion [31]. A correlation study showed a correlation between sebum and pores, that is, pores increase in size as the amount of sebum increases [2] [32]. Another study found similar correlations among the variables. Roh et al. performed a correlation analysis of sebum and pores and found that the sebum output level correlated most significantly with pore size [32]. Yet another study showed a positive relationship between sebum production and pores. Sebaceous glands can number as many as $400-900$ per $\mathrm{cm}^{2}$ on the face. Areas that are commonly affected are those that contain a higher density of sebaceous glands, such as the face, ears, scalp, and upper part of the trunk [33]. According to our data, the neck has higher moisture values than other regions. Slaheddine and colleagues showed that the skin temperature of the neck had the highest value in a young age group, followed by the nasolabial and penoral areas [14]. The nature of the local skin temperature effect on local sweating rate. And other could readily be described by the equation derived from the interrelations between internal and skin temperature and local sweating rate [34]. According to the correlation analysis, wrinkles and pigmentation were positively correlated. Many studies have reported that UV radiation destroys collagen in skin tissue, leading to wrinkle formation [35] [36]. One study investigated the characteristics of cutaneous photo damage in relation to age on Asian skin. The results showed a significant relationship between wrinkles and dyspigmentation at ages 30 - 49 and 50 - 69 [37]. However, our correlation data showed that wrinkles and pigmentation were positively related at ages $20-29$ in healthy men.

\section{Conclusion}

In the present study, our data showed that the changes in skin condition are associated with external stimulants. The effect of ultrasonic stimulation on skin may differ depending on the part of the body, and some biophysical properties of skin vary depending on the location on the body.

\section{Acknowledgements}

We thank to the Yongin University students for supporting this work. There are actively supported by Dan-Ho academy. 


\section{Conflicts of Interest}

The authors declare no conflicts of interest regarding the publication of this paper.

\section{References}

[1] Song, E.J., Lee, J.A., Park, J.J., Kim, H.J., Kim, N.S., Byun, K.S., Choi, G.S. and Moon, T.K. (2015) A Study on Seasonal Variation of Skin Parameters in Korean Males. International Journal of Cosmetic Science, 37, 92-97. https://doi.org/10.1111/ics.12174

[2] Luebberding, S., Krueger, N. and Kerscher, M. (2014) Age-Related Changes in Male Skin: Quantitative Evaluation of One Hundred and Fifty Male Subjects. Skin Pharmacology and Physiology, 27, 9-17. https://doi.org/10.1159/000351349

[3] Le Fur, I., Lopez, S., Morizot, F., Guinot, C. and Tschachler, E. (1999) Comparison of Cheek and Forehead Regions by Bioengineering Methods in Women with Different Self Reported "Cosmetic Skin Types". Skin Research and Technology, 5, 182-188. https://doi.org/10.1111/j.1600-0846.1999.tb00129.x

[4] Mitragotri, S. (2005) Healing Sound: The Use of Ultrasound in Drug Delivery and Other Therapeutic Application. Nature Reviews Drug Discovery, 4, 255-260. https://doi.org/10.1038/nrd1662

[5] Polat, B.E., Hart, D., Langer, R. and Blankschtein, D. (2011) Ultrasound-Mediated Transdermal Drug Delivery: Mechanisms, Scope, and Emerging Trends. Journal of Controlled Release, 152, 330-348. https://doi.org/10.1016/j.jconrel.2011.01.006

[6] Speed, C.A. (2001) Therapeutic Ultrasound in Soft Tissue Lesions. Rheumatology, 40, 1331-1336. https://doi.org/10.1093/rheumatology/40.12.1331

[7] ter Haar, G. (1999) Therapeutic Ultrasound. European Journal of Ultrasound, 9, 3-9. https://doi.org/10.1016/S0929-8266(99)00013-0

[8] Choi, J.W., Choi, B.H., Park, S.H., Pai, K.S., Li, T.Z., Min, B.H. and Park, S.R. (2013) Mechanical Stimulation by Ultrasound Enhances Chondrogenic Differentiation of Mesenchymal Stem Cells in a Fibrin-Hyaluronic Acid Hydrogel. Artificial Organs, 37, 648-655. https://doi.org/10.1111/aor.12041

[9] Kocaoğlu, B., Cabukoglu, C., Ozeras, N., Seyhan, M., Karahan, M. and Yalcin, S. (2011) The Effect of Therapeutic Ultrasound on Metallic Implants: A Study in Rats. Archives of Physical Medicine and Rehabilitation, 92, 1858-1862. https://doi.org/10.1016/j.apmr.2011.06.002

[10] Reher, P., Doan, N., Bradnock, B., Meghji, S. and Harris, M. (1999) Effect of Ultrasound on the Production of IL-8, Basic FGF and VEGF. Cytokine, 11, 416-423. https://doi.org/10.1006/cyto.1998.0444

[11] Pounder, N.M. and Harrison, A.J. (2008) Low Intensity Pulsed Ultrasound for Fracture Healing: A Review of the Clinical Evidence and the Associated Biological Mechanism of Action. Ultrasonics, 48, 330-338. https://doi.org/10.1016/j.ultras.2008.02.005

[12] van der Windt, D.A., van der Heijden, G.J., van den Berg, S.G., ter Riet, G., de Winter, A.F. and Bouter, L.M. (1999) Ultrasound Therapy for Musculoskeletal Disorders: A Systematic Review. Pain, 81, 257-271. https://doi.org/10.1016/S0304-3959(99)00016-0

[13] Man, M.Q., Xin, S.J., Song, S.P., Cho, S.Y., Zhang, X.J., Tu, C.X., Feingold, K.R. and Elias, P.M. (2009) Variation of Skin Surface pH, Sebum Content and Stratum Corneum Hydration with Age and Gender in a Large Chinese Population. Skin Phar- 
macology and Physiology, 22, 190-199. https://doi.org/10.1159/000231524

[14] Firooz, A., Sadr, B., Babakoohi, S., Sarraf-Yazdy, M., Fanian, F., Kazerouni-Timsar, A., Nassiri-Kashani, M., Naghizadeh, M.M. and Dowlati, Y. (2012) Variation of Biophysical Parameters of the Skin with Age, Gender, and Body Region. The Scientific World Journal, 2012, 1-5. https://doi.org/10.1100/2012/386936

[15] Fu, J.J., Hillebrand, G.G., Raleigh, P., Li, J., Marmor, M.J., Bertucci, V., Grimes, P.E., Mandy, S.H., Perez, M.I., Weinkle, S.H. and Kaczvinsky, J.R. (2010) A Randomized, Controlled Comparative Study of the Wrinkle Reduction Benefits of a Cosmetic Niacinamide/Peptide/Retinyl Propionate Product Regimen vs. a Prescription 0.02\% Tretinoin Product Regimen. British Journal of Dermatology, 162, 647-654. https://doi.org/10.1111/j.1365-2133.2009.09436.x

[16] Ezerskaia, A., Pereira, S.F., Urbach, H.P., Verhagen, R. and Varghese, B. (2016) Quantitative and Simultaneous Non-Invasive Measurement of Skin Hydration and Sebum Levels. Biomedical Optics Express, 7, 2311-2320.

https://doi.org/10.1364/BOE.7.002311

[17] Bertuccelli, G., Zerbinati, N., Marcellino, M., Nanda Kumar, N.S., He, F., Tsepakolenko, V., Cervi, J., Lorenzetti, A. and Marotta, F. (2016) Effect of a Quality-Controlled Fermented Nutraceutical on Skin Aging Markers: An Antioxidant-Control, Double-Blind Study. Experimental and Therapeutic Medicine, 11, 909-916. https://doi.org/10.3892/etm.2016.3011

[18] Wang, F., Garza, L.A., Cho, S., Kafi, R., Hammerberg, C., Quan, T., Hamilton, T., Mayes, M., Ratanatharathorn, V., Voorhees, J.J., Fisher, G.J. and Kang, S. (2008) Effect of Increased Pigmentation on the Antifibrotic Response of Human Skin to UV-A1 Phototherapy. Archives of Dermatological Research, 144, 851-858.

[19] Lee, S.H., Choi, E.H., Feingold, K.R., Jiang, S. and Ahn, S.K. (1998) Iontophoresis Itself on Hairless Mouse Skin Induces the Loss of the Epidermal Calcium Gradient without Skin Barrier Impairment. Journal of Investigative Dermatology, 111, 39-43. https://doi.org/10.1046/j.1523-1747.1998.00226.x

[20] Pedersen, L.K. and Jemec, G.B. (1999) Plasticising Effect of Water and Glycerin on Human Skin in Vivo. Journal of Dermatological Science, 19, 48-52. https://doi.org/10.1016/S0923-1811(98)00050-4

[21] Lodén, M. and Wessman, W. (2001) The Influence of a Cream Containing 20\% Glycerin and Its Vehicle on Skin Barrier Properties. International Journal of Cosmetic Science, 23, 115-119. https://doi.org/10.1046/j.1467-2494.2001.00060.x

[22] Li, F., Conroy, E., Visscher, M. and Wickett, R.R. (2001) The Ability of Electrical Measurements to Predict Skin Moisturization. I. Effects of $\mathrm{NaCl}$ and Glycerin on Short-Term Measurements. Journal of Cosmetic Science, 52, 13-22.

[23] Meyer-Rogge, D., Rösken, F., Holzschuh, P. and Kruglikov, I. (2012) Facial Skin Rejuvenation with High Frequency Ultrasound: Multicentre Study of Dual-Frequency Ultrasound. Journal of Cosmetics, Dermatological Sciences and Applications, 2, 68-73. https://doi.org/10.4236/jcdsa.2012.22016

[24] Orringer, J.S., Voorhees, J.J., Hamilton, T., Hammerberg, C., Kang, S., Johnson, T.M., Karimipour, D.J. and Fisher, G. (2005) Dermal Matrix Remodeling after Nonablative Laser Therapy. Journal of the American Academy of Dermatology, 53, 775-782. https://doi.org/10.1016/j.jaad.2005.07.052

[25] Mester, E., Mester, A.F. and Mester, A. (1985) The Biomedical Effects of Laser Application. Lasers in Surgery and Medicine, 5, 31-39. https://doi.org/10.1002/lsm.1900050105

[26] Khan, M.H., Sink, R.K., Manstein, D., Eimerl, D. and Anderson, R.R. (2005) Intra- 
dermally Focused Infrared Laser Pulses: Thermal Effects at Defined Tissue Depths. Lasers in Surgery and Medicine, 36, 270-280. https://doi.org/10.1002/1sm.20142

[27] Takiwaki, H., Shirai, S., Kohno, H., Soh, H. and Arase, S. (1994) The Degrees of UVB-Induced Erythema and Pigmentation Correlate Linearly and Are Reduced in a Parallel Manner by Topical Anti-Inflammatory Agents. Journal of Investigative Dermatology, 103, 642-646. https://doi.org/10.1111/1523-1747.ep12398276

[28] Holick, M.F. (2016) Biological Effects of Sunlight, Ultraviolet Radiation, Visible Light, Infrared Radiation and Vitamin D for Health. Anticancer Research, 36, $1345-1356$.

[29] Marrakchi, S. and Maibach, H.I. (2007) Biophysical Parameters of Skin: Map of Human Face, Regional, and Age-Related Differences. Contact Dermatitis, 57, 28-34. https://doi.org/10.1111/j.1600-0536.2007.01138.x

[30] Cunliffe, W.J., Burton, J.L. and Shuster, S. (1970) The Effect of Local Temperature Variations on the Sebum Excretion Rate. British Journal of Dermatology, 83, 650-654. https://doi.org/10.1111/j.1365-2133.1970.tb15759.x

[31] Williams, M., Cunliffe, W.J., Williamson, B., Forster, R.A., Cotterill, J.A. and Edwards, J.C. (1973) The Effect of Local Temperature Change on Sebum Excretion Rate and Forehead Surface Lipid Composition. British Journal of Dermatology, 88, 257-262. https://doi.org/10.1111/j.1365-2133.1973.tb07544.x

[32] Roh, M., Han, M., Kim, D. and Chung, K. (2006) Sebum Output as a Factor Contributing to the Size of Facial Pores. British Journal of Dermatology, 155, 890-894. https://doi.org/10.1111/j.1365-2133.2006.07465.x

[33] Picardo, M., Ottaviani, M., Camera, E. and Mastrofrancesco, A. (2009) Sebaceous Gland Lipids. Dermato-Endocrinology, 1, 68-71. https://doi.org/10.4161/derm.1.2.8472

[34] Nadel, E.R., Bullard, R.W. and Stolwijk, J.A. (1971) Importance of Skin Temperature in the Regulation of Sweating. Journal of Applied Physiology, 31, 80-87. https://doi.org/10.1152/jappl.1971.31.1.80

[35] Pillai, S., Oresajo, C. and Hayward, J. (2005) Ultraviolet Radiation and Skin Aging: Roles of Reactive Oxygen Species, Inflammation and Protease Activation, and Strategies for Prevention of Inflammation-Induced Matrix Degradation-A Review. International Journal of Cosmetic Science, 27, 17-34. https://doi.org/10.1111/j.1467-2494.2004.00241.x

[36] Battie, C. and Verschoore, M. (2012) Cutaneous Solar Ultraviolet Exposure and Clinical Aspects of Photodamage. Indian Journal of Dermatology, Venereology and Leprology, 78, S9-S14.

[37] Chung, J.H., Lee, S.H., Youn, C.S., Park, B.J., Kim, K.H., Park, K.C., Cho, K.H. and Eun, H.C. (2001) Cutaneous Photodamage in Koreans: Influence of Sex, Sun Exposure, Smoking, and Skin Color. Archives of Dermatological Research, 137, 1043-1051. 